\title{
Gestión de los recursos interactivos
} en los ciberdiarios peruanos

\section{Resumen}

En este artículo se analizan las tendencias en la incorporación de los recursos interactivos en los diarios digitales peruanos de ámbito local y nacional. Mediante el análisis exploratorio de los sitios web se determinan las preferencias comunicativas de los cibermedios, el nivel de aprovechamiento de las herramientas 2.0 y los modelos de uso de las redes sociales.

Palabras clave: periodismo digital, contenido generado por el usuario, UGC, periodismo ciudadano, periodismo participativo, Web 2.0.

\section{The Management of Interactive Features in Peruvian Online Newspapers}

\begin{abstract} of social networks are determined by exploratory analysis of websites

Key words: digital journalism, user-generated content, UGC, citizen journalism, participatory journalism, Web 2.0.
\end{abstract}

This article analyzes the trends in the incorporation of interactive resources in Peruvian digital newspapers of the local and national scope. The communicative preferences of online media, the level of use of Web 2.0 tools, and the usage patterns

Dra. Lyudmyla Yezers'ka

Docente de la Universidad de Piura (UDEP) 


\section{Introducción}

En los últimos diecisiete años, la gran mayoría de los medios de comunicación peruanos han desarrollado las estrategias de su presencia en internet. Desde una perspectiva histórica, diferentes etapas de la evolución y consolidación de las ediciones digitales peruanas no han tenido una delimitación temporal definida.

"Cada medio ha avanzado a su ritmo, dependiendo -entre otros factores- del momento de entrada en la Red, del personal destinado a la publicación y, sobre todo, de la solidez de la empresa periodística y su política respecto a la edición digital" (Yezers'ka, 2008a, 71).

En nuestros días, la expansión de social media y el fenómeno del periodismo ciudadano han inducido a los medios de comunicación a centrar su interés en estas tendencias. Uno de los aspectos más importantes en este momento es el cambio del comportamiento de la audiencia: de los consumidores pasivos de las noticias proporcionadas por los mass media a los usuarios que crean contenidos informativos y participan activamente en el proceso comunicativo global.

La tendencia de incluir las contribuciones de los periodistas ciudadanos (blogs, comentarios, piezas audiovisuales, imágenes, etc.) en los medios digitales ilustran los retos que enfrenta el periodismo frente al contenido generado por el usuario (CGU). Todas las señales apuntan a que los medios de comunicación están en una encrucijada entre el pasado y el futuro y deben hallar fórmulas para producir contenidos polivalentes, capaces de ser distribuidos por distintos soportes y enfrentarse al feedback de los usuarios, que ahora manejan las herramientas participativas y colaborativas (herramientas 2.0).

Estos aspectos demuestran la necesidad de estudiar los procesos de transformaciones que suceden en los medios de comunicación digitales -cara al cambio del paradigma de comunicación- impulsados por el constante desarrollo de la Web 2.0 (la web social). Determinar si los diarios están valorando el rol activo que pudieran tener los usuarios ante la producción informativa y, más aún, caracterizar el conjunto de los instrumentos interactivos que ofrecen en su web, es una tarea que cobra mayor sentido en el campo de la investigación sobre medios online. 
De allí, la intención de esta investigación es reflexionar sobre los procesos que suceden en los medios de comunicación peruanos, tras la entrada en la escena de los nuevos sistemas sociales que impulsan el comportamiento participativo de las audiencias y fijar algunas tendencias. Hasta hace poco, la posibilidad de interpretar al productor de información dentro del propio medio, mediante los recursos interactivos, resultaba una novedad. Ahora, los principales medios de comunicación a nivel mundial tienden a dar una mayor importancia y visibilidad a la participación de los usuarios mediante la incorporación en sus sitios web de las plataformas CGU. Como reitera Orihuela (2011),

"Pasaron ya los tiempos en los que la Web era una plataforma de consulta, los buscadores la herramienta estrella y el posicionamiento la clave del tráfico. En esta época de medios sociales, la Web se ha convertido en una plataforma de participación, las redes sociales son las herramientas estrella y las recomendaciones que sugerimos y recibimos en ellas comienzan a emerger como nuevas claves de tráfico".

En este trabajo se tomaron como referencia los resultados de las investigaciones anteriores, emprendidas en 2002, dedicadas al análisis del impacto que produce internet en el periodismo en general, y en los medios de comunicación en Perú, en particular.

No obstante, el acceso masivo a los equipos digitales y de libre disposición de las herramientas colaborativas que permiten a las personas crear contenidos audiovisuales de manera sencilla, así como creciente popularidad de redes sociales, inducen a renovar ${ }^{1}$ el interés de los

${ }^{1}$ Las investigaciones anteriores sobre la interactividad en los medios peruanos fueron realizadas por las profesoras de la Universidad de Piura Rosa Zeta (2002) y Lyudmyla Yezers'ka (2008b) y se refieren a los años 2002 y 2005 respectivamente, es decir, la etapa del "Periodismo 1.0", según la calificación de Juan Varela (2004), cuando los medios digitales aún no consideraban la posibilidad de colaboración de la audiencia en sus sitio web. 
investigadores por los conceptos de interactividad y colaboración de los usuarios en los medios de comunicación. Pues la participación ciudadana en la agenda informativa de los medios periodísticos contribuye al desarrollo de la democracia y la libertad de expresión.

\section{Los aspectos teóricos}

El concepto de interactividad tiene sus orígenes en la creación de la informática y se refiere a la "capacidad de las computadoras por responder a los requerimientos de los usuarios" (Rost, 2004). No obstante, con la aparición de los medios digitales, a este enfoque netamente técnico han sido añadidos otros vínculos que aluden más bien a las relaciones entre las fuentes informativas (periódicos, radios, canales televisivos) y los usuarios.

Díaz Noci (2001) parte de la idea de que la interactividad es la "posibilidad de que el receptor actúe en mayor o menor medida sobre el mensaje que se le envía", es decir, la posibilidad de integrar al lector como partícipe del sistema comunicativo y no solo como un mero espectador. Con la interactividad se rompe el concepto de medio de comunicación de masas, cuando el mensaje era unidireccional.

"El receptor tiene así plena potestad para tomar decisiones, y configurar, dentro de unos límites amplios, su propio mensaje, así como para dialogar, de una forma u otra, con el emisor" (Díaz Noci, 2001: 96).

Cuando el lector dispone de la oportunidad de seleccionar la ruta de su navegación en la edición digital a través de los enlaces, pero no puede manipular los contenidos informativos, esto se considera el nivel básico de la interactividad. El grado de interactividad en los cibermedios puede alcanzar niveles más altos y complejos cuando se establece el diálogo entre el periodista y lector, o entre los lectores, o cuando se consulta el archivo de números atrasados de un diario. 
Principalmente estas tendencias en ofrecer los espacios informativos para las contribuciones de los usuarios e integración de estos contenidos en los espacios reservados anteriormente a los profesionales, presentan para García de Torres (2010) la novedad y un especial interés para investigar.

Este proceso se acompaña por una serie de fenómenos como blogs, redes sociales, servicios, aplicaciones y nuevos usos sociales en general. El concepto de co-producción-colaboración de la audiencia en la elaboración de contenidos (UGC)- está estrechamente vinculado al desarrollo de las herramientas 2.0.

\section{Objetivos y metodología de la investigación}

El estudio de las actividades interactivas de los usuarios en los medios digitales en general no es novedoso. El tema de la interactividad fue el objeto de interés de numerosas publicaciones (Orihuela y Santos, 1999; Sádaba, 2000; Pavlik, 2001; Rost, 2004, Salaverría, 2005, entre otros), lo que confirma la importancia de este aspecto para el periodismo. No obstante, los recursos interactivos en los medios digitales de la primera década del ciberperiodismo (1995-2005) fueron limitados principalmente a herramientas como los grupos de noticias, correos electrónicos, foros de discusión, encuestas y zonas de charlas.

Al abordar el tema de la interactividad hoy día, debemos tener en cuenta que el periódico digital se está convirtiendo en una plataforma donde confluyen usuarios que, además de consumir, participan -lo que llamamos periodismo participativo- y producen información -lo que llamamos periodismo colaborativo.

El objetivo principal de esta investigación es analizar la evolución de la incorporación de las herramientas interactivas (Web 2.0) en los diarios digitales peruanos y detectar las principales tendencias.

En cuanto al método, optamos por una evaluación exploratoria de los sitios web y el análisis de la presencia de los principales recursos interactivos clasificados en 20 variables, las mismas que aplicamos en 
el año 2009 al grupo de los ciberdiarios nacionales (Yezers'ka, 2009). Esta decisión fue tomada principalmente porque permite contar con los puntos de comparación, contrastar los resultados y obtener una perspectiva de la evolución de los medios peruanos en la red².

Se anota, además de la presencia/ausencia de estas variables, los condicionamientos de participación en áreas abiertas a los usuarios. Considerando la aceptación masiva que tienen ahora las redes sociales como un nuevo sistema comunicativo y un canal de distribución de contenidos, analizamos el uso que dan los cibermedios peruanos a estos recursos. Se visitaron las opciones de compartir de cada uno de los sitios web y se contabilizaron las redes sociales con las que permitían difundir su información.

De esta manera, en el primer trimestre del 2011 se hizo un análisis exploratorio de las 20 ediciones digitales de los periódicos de información general, de ámbito nacional (10) y regional (10), de pago y con más amplia circulación en el mercado, de acuerdo con los indicadores del informe Market Report (CPI, 2010). En la Tabla 1 se presenta el listado de los periódicos peruanos seleccionados en orden descendiente de acuerdo al índice de lectoría (Rating) y separados por el ámbito de difusión.

2 Las investigaciones anteriores sobre la interactividad en los medios peruanos fueron realizadas por las profesoras de la Universidad de Piura Rosa Zeta (2002) y Lyudmyla Yezers'ka (2008b) y se refieren a los años 2002 y 2005 respectivamente, es decir, la etapa del "Periodismo 1.0", según la calificación de Juan Varela (2004), cuando los medios digitales aún no consideraban la posibilidad de colaboración de la audiencia en sus sitio web.

A la hora de seleccionar las variables, tomamos como referencia la investigación internacional "UGC Status and Levels of Control in Argentine, Colombian, Mexican, Peruvian, Portuguese, Spanish, US and Venezuelan Online Newspapers" (García de Torres, et. al, 2009). Las variables seleccionadas para el análisis son Vídeo, Redes sociales, Encuestas, Más Popular/Leído/Respondido, RSS, Marcadores, Comentarios en las noticias, Normas, Moderador, Vota noticia, Comentarios en los blogs, Blogs de periodistas, Comunidad de usuarios, Fotos enviados por usuarios, Video enviados por usuarios, Noticias creadas por usuarios, Foros, UGC, blogs de usuarios, Podcast. 
Tabla 1. Muestra de los diarios seleccionados para el análisis

\begin{tabular}{|l|l|c|c|c|}
\hline Ciudad & \multicolumn{1}{|c|}{ Diario } & Difusión & Rtg. (\%) & Mls. \\
\hline Lima & Trome & nacional & 20.1 & 1297.2 \\
\hline Lima & Ojo & nacional & 8.8 & 566.4 \\
\hline Lima & El Comercio & nacional & 8.6 & 555.3 \\
\hline Lima & Perú.21 & nacional & 4.4 & 282.4 \\
\hline Lima & Aja & nacional & 3.9 & 251 \\
\hline Lima & El Popular & nacional & 2.7 & 175.9 \\
\hline Lima & La República & nacional & 1.8 & 116.7 \\
\hline Lima & La Razón & nacional & 1.4 & 89.1 \\
\hline Lima & El Chino & nacional & 0.8 & 49.4 \\
\hline Lima & Expreso & nacional & 0.7 & 43.8 \\
\hline Huancayo & Correo & regional & 35.7 & 90.1 \\
\hline Piura & La Hora & regional & 30 & 105.9 \\
\hline Tarapoto & Ahora & regional & 23.7 & 21.2 \\
\hline Trujillo & Satélite & regional & 11.4 & 62.3 \\
\hline Piura & El Tiempo & regional & 10.6 & 37.2 \\
\hline Cusco & El Sol & regional & 9.7 & 26.3 \\
\hline Iquitos & La Región & regional & 7.9 & 21.1 \\
\hline Chimbote & El Diario de Chimbote & regional & 7.1 & 17.5 \\
\hline Cajamarca & Panorama Cajamarquino & regional & 7 & 9 \\
\hline Trujillo & La Industria & regional & 6.9 & 37.7 \\
\hline & & & & \\
\hline
\end{tabular}

Las hipótesis se apoyan en los estudios previos de los ciberdiarios nacionales. En anteriores trabajos obtuvimos resultados que nos permitieron detectar una falta de homogeneidad en el desarrollo de los periódicos y establecer dos modelos de diarios, atendiendo el nivel de dinamismo que presentaban sus sitios web: 'dinámicos' son aquellos que diversifican su actividad informativa, aprovechan las potencialidades del soporte digital en mayor medida y se diferencian de la edición convencional; y 'dependientes', los que repiten los patrones de su edición tradicional y no intentan innovar con las tendencias y avances tecnológicos y comunicativos (Yezers'ka, 2012: 284-286). 


\section{Principales resultados}

Este estudio ha permitido determinar de manera empírica las principales tendencias en la dinámica de participación de la audiencia en las publicaciones digitales de los periódicos peruanos y dar una visión del estado de los diarios digitales en el momento concreto de su evolución. Con la finalidad de conocer la oferta de los recursos interactivos, así como el grado de uso de redes sociales, en los meses enero - marzo del 2011 fueron explorados los sitios web de los 20 periódicos de mayor lectoría a nivel nacional y regional.

No obstante, para comprender el nivel a que ha llegado el desarrollo de los medios digitales en Perú, al igual que en otros países latinoamericanos, es necesario atender tanto la situación socioeconómica como tecnológica. Son las coordenadas que ayudan a situar en un contexto real e interpretar con una mayor seguridad los fenómenos comunicativos que se presentan en el país ${ }^{3}$.

\subsection{Entorno tecnológico}

En cuanto a la situación socioeconómica y tecnológica, el país sigue presentando varios indicadores desfavorables. Uno de los factores que influye de manera importante en la evolución y progreso del periodismo digital es el estado de desarrollo de las nuevas tecnologías de la información y comunicación (TIC).

El último Informe Global sobre Tecnología, realizado por el Foro Económico Mundial (FEM, 2012), destacó un retroceso de la mayoría de los países de Latinoamérica en cuanto a la capacidad tecnológica. Según el ranking mundial presentado en el informe, Perú en su desarrollo

3 Tal como indicaba Pablo J. Boczkowski (2006: 31), los medios de comunicación en internet surgen mediante la "fusión de infraestructuras sociomateriales existentes y capacidades técnicas novedosas"; y la evolución de estos medios depende de la "combinación de condiciones históricas, contingencias locales y la dinámica del proceso". 
tecnológico, se encuentra detrás de los 11 países latinoamericanos y ocupa el puesto 106 (ha retrocedido los 14 puestos durante el último año) con el índice de la competitividad tecnológica (ICT) 3,34 (3,38 el año pasado) $)^{4}$.

Tampoco favorece al desarrollo del periodismo digital el bajo índice de acceso de los peruanos a las nuevas tecnologías. De acuerdo con las estadísticas del Instituto Nacional de Estadística e Informática (INEI), aunque la cuarta parte de los hogares peruanos $(26,3 \%)$ cuenta al menos con una computadora, solo el 17,7\% tiene acceso a internet (Figura 1). Tal y como se ha detectado en los estudios anteriores (Yezers'ka, 2008), el acceso de los peruanos a las nuevas tecnologías varía significativamente en función del área de residencia. Mientras que en Lima Metropolitana el $35 \%$ de los hogares tienen internet, en el resto urbano se registra el 15,2\%; en el área rural apenas el 0,5\% están conectados (INEI, 2011).

Figura 1. Acceso de los hogares peruanos a las TIC

(INEI, 2009; 2010; 2011).

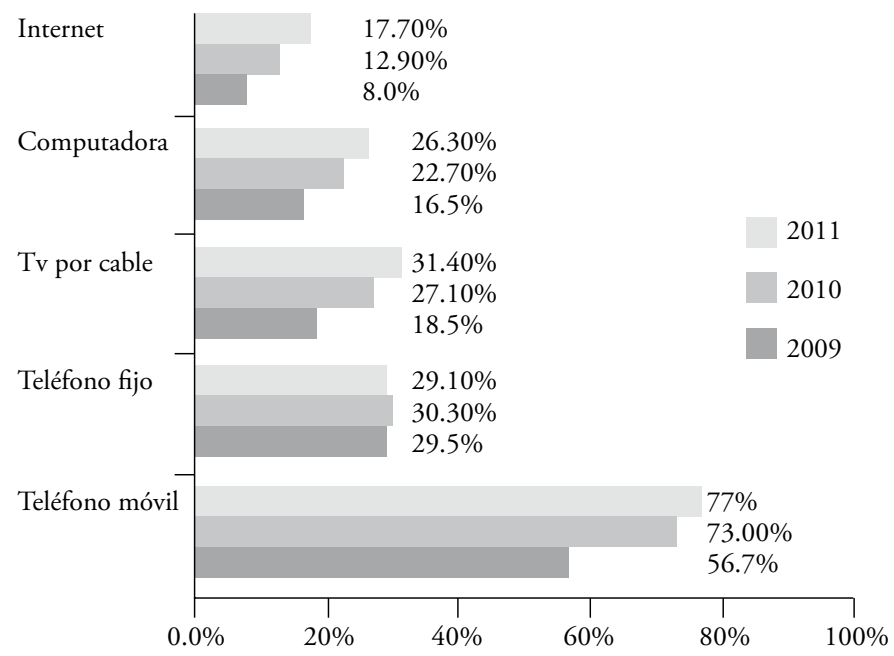

Fuente: INEI (2009; 2010; 2011), elaboración propia.

${ }^{4}$ Sólo dos países de la región se encuentran entre los primeros 50 puestos del ranking: Chile (puesto 39) y Uruguay (puesto 44). 
Sin embargo, como se puede ver en la Figura 1, el nivel de acceso de los hogares peruanos a las nuevas tecnologías de la información y comunicación tiene tendencia de incremento con el paso de los años. Así, el acceso de los hogares a internet ha crecido en 4.8 puntos porcentuales en comparación con el año 2010, mientras que de la telefonía móvil en 4 puntos porcentuales. El único medio de comunicación interpersonal que tuvo un ligero retroceso en las preferencias de los peruanos es el teléfono fijo que está siendo reemplazado cada vez más con la telefonía móvil y las aplicaciones sociales.

Es importante recordar que el uso de internet en Perú se ha difundido no a través de la tenencia de computadoras en el hogar, como en los países desarrollados, sino por el uso de las cabinas públicas. Actualmente, más de la mitad $(54,5 \%)$ de la población que accede a internet lo realiza en los establecimientos comunitarios, un porcentaje menor en 8,5 puntos porcentuales al registrado el año $2010(63,0 \%)$.

Sin duda es uno de los factores que ha favorecido al incremento del número de usuarios de internet a nivel nacional que ha crecido de 8 mil en el año 1995 a más que 10 millones (36,4\% de la población) en el 2012.

Otro factor importante se refiere a la incursión, a lo largo de los últimos años, de las herramientas sociales -blogs, redes sociales, software libre- que introducen un cambio radical en el comportamiento de la audiencia, así como en el modo de consumir los medios de comunicación. Las estadísticas muestran que la gran mayoría de los internautas peruanos (75,3\% según INEI, 2011) navega para comunicarse por email, chat, redes sociales, etc. El 65,8\% consumen internet para entretenerse con juegos y bajar películas y música, mientras que para la educación y capacitación lo usan solo el 9\%. En cuanto a los internautas limeños, el $74,5 \%$ navegan para comunicarse, el $40,1 \%$ para entretenimiento y 30,8\% para obtener información y ver las noticias (CPI, 2012: 4).

Son los aspectos que de una u otra manera influyen en el desarrollo de los fenómenos comunicativos que suceden actualmente en internet a nivel mundial y que se analizan en los siguientes puntos. 


\subsection{Presencia de los recursos interactivos en los ciberdiarios peruanos}

En lo relativo al conjunto de herramientas interactivas que los ciberdiarios examinados han incorporado en sus sitios web (Figura 2), las redes sociales son más representativas, pues el 70\% de los periódicos las usan. Encuesta (50\%), la opción más destacada en 2009 en los diarios nacionales (70\%), es superada ahora por dos variables: redes sociales y videos (65\%).

Solo la mitad de los periódicos prestan atención a la opinión que tienen los lectores sobre las noticias publicadas, mediante el listado de los artículos Más Popular/Leído/Respondido. El acceso a la información en la web a través de los servicios RSS ofrece el 50\% de los medios estudiados, los marcadores incorporan el $45 \%$ de las cabeceras, mientras que la posibilidad de comentar las noticias está presente en $40 \%$.

Por lovisto, los modelos de regulación de los comentariosylas publicaciones de los usuarios aún no están explorados en la mayoría de los ciberdiarios, pues solo el $25 \%$ de ellos publican las normas de uso de los servicios de participación y ejercen algún tipo de moderación de los contenidos.

Figura 2. Recursos interactivos en los ciberdiarios peruanos

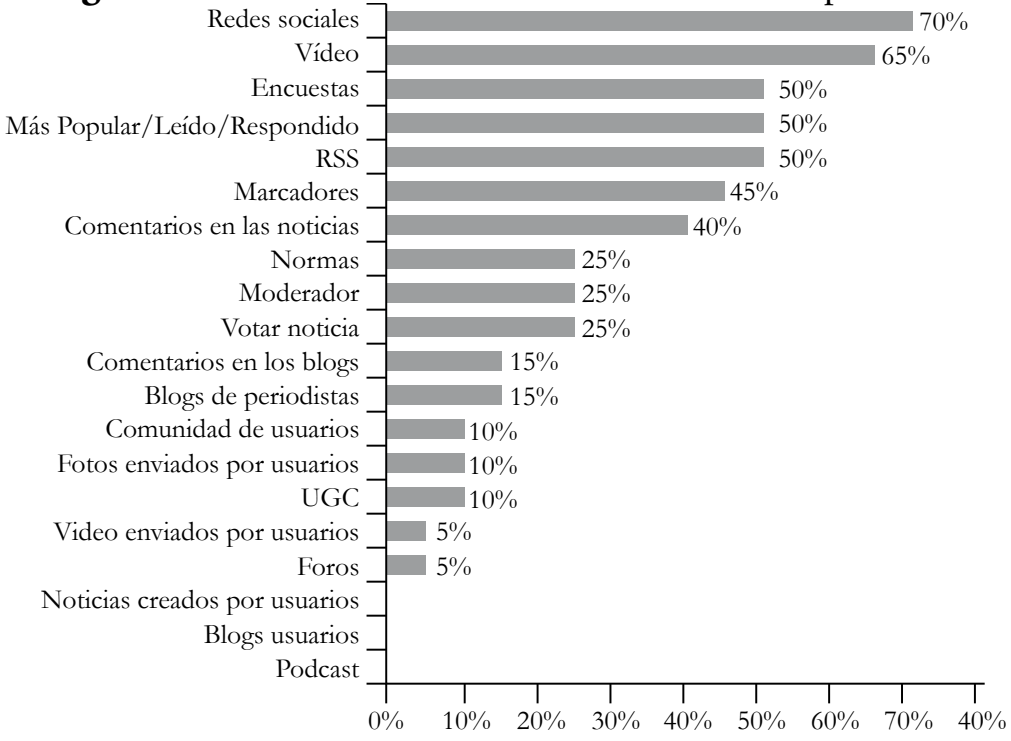

Fuente: Datos del estudio (2011 - I), elaboración propia 
Por otro lado, se nota que los medios aún no confían en la posibilidad de que los usuarios puedan aportar contenidos informativos de interés. En cuanto a los blogs de periodistas, se mantienen solo en tres ciberdiarios nacionales, mientras que los espacios para UGC y las comunidades ofrecen dos de ellos. Solo un periódico publica en su sitio web los vídeos de usuarios, subidos previamente a la plataforma de Youtube. Los foros que fueron muy comunes en los años anteriores, se encontraron solo en un cibermedio, pues fueron sustituidos por redes sociales.

A diferencia de los estudios anteriores, el presente analiza tanto los periódicos con cobertura nacional, como de ámbito regional. Al separar los resultados de este estudio entre ciberdiarios nacionales y regionales, encontramos unas diferencias notorias en cuanto a la presencia y el uso de las herramientas 2.0 (Tabla 2).

Según resultados, los medios digitales nacionales utilizan el $85 \%$ de los recursos interactivos evaluados, mientras que los regionales aprovechan solo el $45 \%$ de estos. Entre las herramientas más usadas en los medios regionales se encuentran los vídeos $(60 \%)$, las redes sociales (60\%), RSS (40\%) y las valoraciones Más Popular/Leído/Respondido (40\%). La posibilidad de comentar las noticias ofrece tres cabeceras. Ninguno de los diarios locales incluye blogs ni comunidades ni acepta las aportaciones de la audiencia (UGC).

Tabla 2. Presencia de los recursos interactivos en diarios nacionales y regionales

\begin{tabular}{|l|c|c|}
\hline Recursos interactivos & Diarios nacionales & Diarios regionales \\
\hline Redes sociales & $80 \%$ & $60 \%$ \\
Vídeos & $70 \%$ & $60 \%$ \\
Marcadores & $60 \%$ & $30 \%$ \\
RSS & $60 \%$ & $40 \%$ \\
Comentarios & $50 \%$ & $30 \%$ \\
Blogs de periodistas & $30 \%$ & 0 \\
Comunidades & $20 \%$ & 0 \\
UGC & $20 \%$ & 0 \\
\hline
\end{tabular}

Fuente: Datos del estudio (2011 - I), elaboración propia 


\subsection{Aprovechamiento de los recursos interactivos}

A la hora de definir el nivel de aprovechamiento de los recursos interactivos en los diarios estudiados, se han tomado en cuenta contenidos presentados en la portada, por ser la página más importante del sitio web. Sin embargo, si el estudio lo requería, revisamos también las páginas vinculadas. Los datos registrados mediante la observación de la presencia de las herramientas 2.0 han permitido valorar el nivel de su uso por cada medio evaluado.

La Figura 3 muestra una "foto fija" del estado de aprovechamiento de las variables interactivas por los ciberdiarios nacionales en el primer trimestre del 2011. El aspecto que cabe mencionar es la tendencia a un desarrollo desigual que se evidencia de manera gráfica. Contrario a los años anteriores (2005 y 2009), se puede diferenciar no dos, sino tres grupos: el grupo de los sitios más dinámicos, los que en mayor medida aprovechan recursos interactivos (más del 50\% de las herramientas): La República, El Comercio y Perú.21. Les siguen los ciberdiarios que aprovechan más del 25\% de las potencialidades interactivas: Trome, Expreso, Ojo y Ajá. El tercer grupo enmarcan los diarios que prácticamente no incluyen los recursos interactivos y desaprovechan las potencialidades del soporte. $\mathrm{La}$ Razón, El Chino y El Popular repiten patrones de su edición tradicional.

Figura 3. Aprovechamiento de los recursos interactivos por los ciberdiarios nacionales

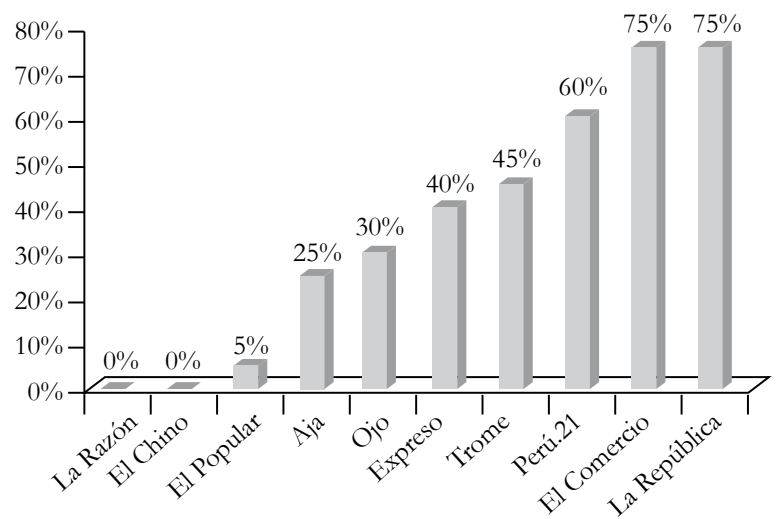

Fuente: Datos del estudio (2011 - I), elaboración propia 
En cuanto a los diarios locales, los datos de investigación presentados en la № Figura 4 confirman el uso deficiente de los recursos interactivos. El diario que mayor uso hace es Correo (30\%), seguido por La Región (25\%).

Figura 4. Nivel de aprovechamiento de los recursos interactivos en los diarios locales

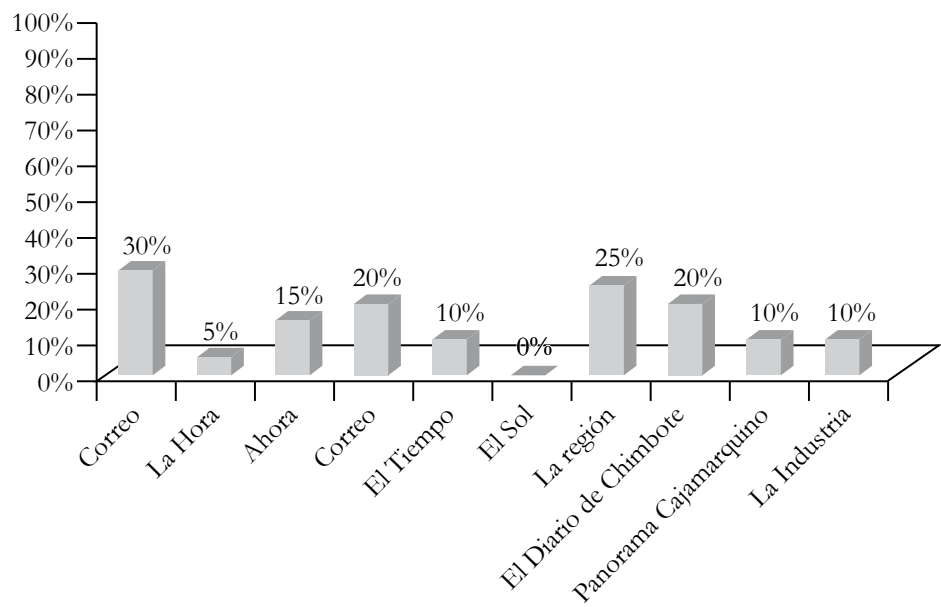

Fuente: Datos del estudio (2011 - I), elaboración propia

En el caso de los diarios nacionales, fue posible fijar la dinámica de la incorporación de las nuevas herramientas comparando los resultados con el año 2009 (Figura 5).

En general, en 2011 se evidencia un aumento en la incorporación de herramientas 2.0 en el conjunto de los 10 diarios examinados, coincidiendo con la hipótesis planteada. La mitad de las cabeceras nacionales han mostrado una evolución notable de interactividad en sus ediciones en la red. Los tres diarios han dado un salto brusco, pasando de la mínima a la amplia incorporación de los avances tecnológicos (Trome, Expreso, Ojo). En el caso de Ajá, se nota una reducción en 10\% del conjunto de las variables presentes en la web. Mientras que los diarios La Razón y El Chino no han evolucionado, El Popular ha crecido un 5\%. 
Figura 5. Nivel de aprovechamiento de los principales recursos interactivos en los diarios nacionales (comparativa entre 2009 y 2011)

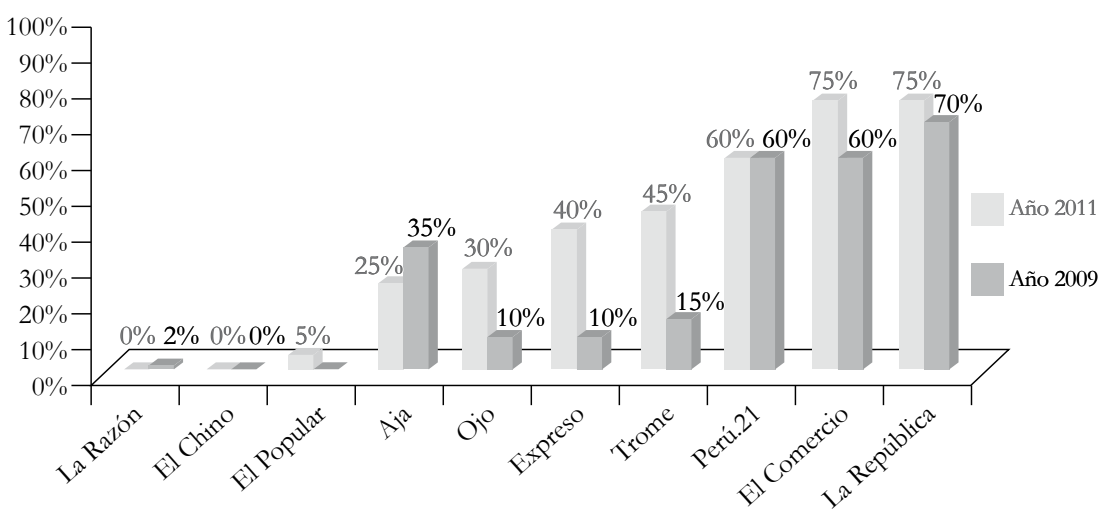

Fuente: Datos del estudio (octubre 2009 y 2011 - I), elaboración propia

\subsection{El uso de redes sociales}

Según los datos del estudio, la mayor parte de los medios peruanos $(70 \%)$ ha incorporado redes sociales a sus servicios informativos. Esta participación se canaliza principalmente por dos vías. La primera es crear una cuenta en la red social (o página en el caso de Facebook) y agregar a los usuarios con el fin de promocionar o fidelizar a sus lectores. De esta manera, los medios aprovechan la oportunidad de distribuir sus contenidos entre una comunidad determinada, donde se forman grupos unidos por su interés particular en el medio, e interactuar con la audiencia. Para el medio esto significa que no solo debe publicar los contenidos en la edición digital, sino también completar la información en las redes sociales a las que se han agregado.

La segunda vía consiste en potenciar la red como plataforma de lanzamiento o distribución de sus contenidos y generar de esta manera un mayor tráfico. En este caso, en la página web se incorpora la oportunidad de compartir directamente estos contenidos desde el propio medio mediante redes sociales $\mathrm{u}$ otras herramientas. 
En cuanto al primer caso, los resultados de la investigación muestran que el $70 \%$ de los diarios digitales mantiene una página en Facebook, el 65\% tiene cuenta oficial en Twitter y el 15\% cuenta con un canal en Youtube. Cabe destacar que las cabeceras peruanas reconocen la importancia del uso de las redes sociales, pues la mayoría de los diarios $(60 \%)$ las presentan en la portada.

En cuanto a la segunda opción, el $65 \%$ de los diarios investigados ofrece varias oportunidades de compartir las noticias publicadas mediante distintas herramientas sociales. Sin embargo, los tres medios nacionales y cuatro regionales no estiman oportuno compartir los contenidos publicados en la web mediante redes sociales. Los recursos sociales para compartir la información se presentan en la Figura 6. Entre las herramientas más usadas destacan e-mail (55\%), Facebook (55\%), Twitter (50\%), Google Bookmarks (40\%), Delicious (30\%) y MySpace (30\%).

Figura 6. Principales recursos interactivos para compartir las noticias

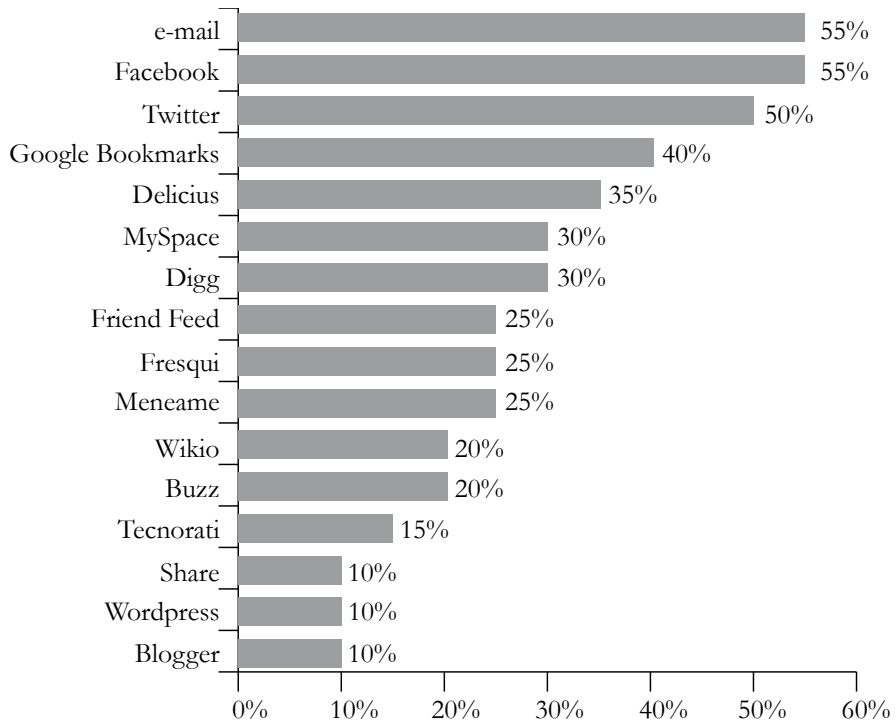

Fuente: Datos del estudio (2011 - I), elaboración propia 
A la hora de separar los resultados entre diarios nacionales y regionales, una vez más se destacan las diferencias que evidencian un mayor desarrollo de los diarios de difusión nacional. La gran mayoría (70\%) de los cibermedios nacionales permite compartir noticias mediante e-mail y Facebook, mientras que solo el $40 \%$ de los periódicos regionales ofrece estas posibilidades en sus sitios web. En el caso de Twitter, la proporción es $60 \%$ de los diarios nacionales y $40 \%$ de los diarios regionales. Asimismo, la mitad de los ciberdiarios nacionales permite usar marcadores sociales como Google bookmarks y Delicious, mientras que en el caso de los regionales son $30 \%$ y $20 \%$. Las mismas tendencias rigen en cuanto a la incorporación de otras herramientas sociales.

\section{Conclusiones}

Los ciberdiarios peruanos dan muestra de un creciente dinamismo en internet en los últimos años. En general, en 2011 se evidencia un aumento en la incorporación de los recursos interactivos en el conjunto de 20 diarios examinados, lo que supone la entrada de la audiencia en la producción informativa. Entre las principales características de los ciberdiarios se puede destacar un mayor aprovechamiento de los elementos multimedia, nuevos recursos interactivos, y una participación activa en las redes sociales. Sin embargo, no todos los periódicos siguen esta tendencia.

Existen diferencias notables en el nivel de aprovechamiento de la interactividad y la participación de los usuarios entre los ciberdiarios nacionales y regionales. Mientras que los primeros utilizan el $85 \%$ de las variables analizadas en esta investigación e intentan abrir los espacios de opinión e incluso colaboración (en algunos casos), los segundos se contentan con la incorporación de la mitad de las herramientas y se limitan con las opciones básicas de compartir los contenidos publicados por el medio.

Los periódicos nacionales siguen presentando la tendencia a un desarrollo desigual de sus ediciones digitales, desde el enfoque de aceptación de la participación como un nuevo modelo informativo. 
Dentro del grupo de ciberdiarios investigados, se destacan los perfiles de los medios que siguen evolucionando e innovando, a través de sus servicios informativos que ocupan una posición significativa en la red, experimentan con nuevos formatos y modelos interactivos. También hay medios que aún se encuentran en la etapa de desarrollo básico (Periodismo 1.0) caracterizada por la similitud en formas, contenidos y estrategias informativas con la versión impresa.

Los datos de la investigación reflejan que la presencia de los cibermedios, tanto nacionales como regionales, en las redes sociales es mayoritaria. Los medios examinados tratan de aprovechar el potencial de estas plataformas virtuales como fuentes de información, promoción y difusión de contenidos periodísticos. Facebook y Twitter destacan en el conjunto de los denominados social media por su capacidad de crear comunidades, fidelizar las audiencias y compartir información.

$\underline{\text { Referencias }}$

Boczkowski, P. J. (2006). Digitalizar las noticias. Innovación en los diarios online. Buenos Aires, Argentina: Ediciones Manantial SRL.

Compañía Peruana de Estudios de Mercados y Opinión Pública (2010). Market Report. Enero 2010. Lima, Perú: CPI.

- (2012). Market Report. Internautas limeños. No02/12. Lima, Perú: CPI.

Díaz Noci (2001). La escritura digital. Hipertexto y construcción del discurso informativo en el periodismo. España: Universidad del País Vasco.

Foro Económico Mundial (2012). The Global Information Technology Report 2012. Living in a Hyperconnected World. Consultado el 20 de mayo 2012 en http://www3.weforum.org/ docs/Global_IT_ Report_2012.pdf.

García de Torres, E., Yezers'ka, L., Rojano, M., et al. (2009). UGC Status and Levels of Control in Argentine, Colombian, Mexican, Peruvian, Portuguese, Spanish, US and Venezuelan Online Newspapers. Paper presented to the 10 th International Symposium on Online Journalism 
University of Texas at Austin. April, 2009. Disponible en http:// online.journalism.utexas.edu/2009/ papers/Garciaetal09.pdf).

Instituto Nacional de Estadística e Informática. Las Tecnologías de Información y Comunicación en los Hogares (ENAHO), $\mathrm{N}^{\circ} 01$ Marzo2012. Disponible en http://www.inei.gob.pe/web/Biblioinei/ BoletinFlotante.asp?file $=13860$.pdf.

Orihuela, J. L. y Santos, M. L. (1999). Introducción al diseño digital: concepción y desarrollo de proyectos de comunicación. Madrid: Anaya Multimedia, D.L.

- (2008). La hora de las redes sociales. Nueva Revista, N¹19, 57-62.

- (2011). La recomendación social de noticias. Digital medios weblog. Consultado el 1.02.2011 en http://www.abc.es/blogs/jose-luisorihuela/public/post/la-recomendacion-social-de-noticias-7830.asp.

Pavlik, J. V. (2001). Journalism and new media. New York: Columbia University Press.

Rost, A. (2004). Pero, ¿de qué hablamos cuando hablamos de Interactividad? Ponencia en VII Congreso ALAIC, 11-16 de octubre 2004, La Plata, Argentina. http://www.alaic.net/VII_congreso/gt/ gt $18 /$ gt $\% 2018 \% 20$ p16.html.

Sádaba Chalezquer, M. R. (junio, 2000). Interactividad y comunidades virtuales en el entorno de la world wide web. Comunicación y Sociedad. Pmplona: Univerisdad de Navarra, XIII, 1,139-166.

Salaverría, R. (2005). Redacción periodística en internet. Pamplona: Eunsa.

Yezers'ka, L. (2008a). Tendencias de los diarios digitales en Perú. Revista Latina de Comunicación Social, 63, 2008, pp. 71 - 82. España: Universidad de La Laguna de Tenerife (http://www.ull.es/ publicaciones/latina/_2008/07/Lyudmyla.html).

- (2008b). Ciberperiodismo en Perú. Análisis de los diarios digitales. Lima: Editorial San Marcos y Universidad de Piura.

- (2009). Panorama de los cibermedios en Perú. Primer Coloquio internacional de ciberperiodismo en la región. PUCP, Lima. 28-30 de octubre de 2009. http://www.slideshare.net/lyezerska/panorama-delos-cibermedios-peruanos. 
- (2012). Las herramientas de participación en la prensa digital en Perú. En García de Torres (coord.). Cartografía del periodismo participativo. Estudio de las herramientas de participación en la prensa digital de Argentina, Colombia, España, Estados Unidos, Israel, México, Perú, Portugal y Venezuela. Valencia: Tirant humanidades.

Varela, J. (2004). Periodismo 3.0. La revolución hiperlocal se anuncia en un blog. Blog Periodistas 21, (http://periodistas21.blogspot. com/2004/12/periodismo-3.html).

Zeta de Pozo, R. (2002). Opciones interactivas en el periodismo digital peruano. Sala de Prensa, 50, diciembre 2002, año III, vol. 2. 